\title{
The Efficacy of Bilateral Sphenopalatine Ganglion Block under General Anesthesia in Trans-Sphenoidal Endoscopic Hypophysectomy
}

Anesthesia

ENT
*Corresponding Author:

Sawsan Gaber Mohamed

sawsan.saadawy@gmail.com

sawsan.saadawy@yahoo.com

Received for publication December 28, 2019; Accepted January 25, 2020; Published online January 27, 2020

Copyright 2020 The Authors published by Al-Azhar University, Faculty of Medicine, Cairo, Egypt. All rights reserved. This an openaccess article distributed under the legal terms, where it is permissible to download and share the work provided it is properly cited. The work cannot be changed in any way or used commercially.

\section{doi:10.21608/AIMJ.2020.69262}

Departments of ${ }^{l}$ Anesthesia, IC \& pain management, ${ }^{2} E N T$, ${ }^{3}$ Neurosurgery, Faculty of Medicine for Girls Al-Azhar University, Cairo, Egypt.

\section{ABSTRACT}

Background: The most important goal in endoscopic pituitary surgery is bloodless field with better visualization under hemodynamic stability and good analgesia to improve the outcome, the current study was performed to evaluate the intraoperative anesthetic and postoperative analgesic effects of bilateral sphenopalatine ganglion block(SPGB)as adjuvant to general anesthesia in endoscopic transsphenoidal resection of pituitary adenoma.

Patients and methods: Thirty patients(ASA I-II)aged 22-55 years, randomly assigned into two equal groups. After stabilization of general anesthesia, the patients received bilateral sphenopalatine ganglion block with $2 \mathrm{ml}$ of either2\% lidocaine: 1:200000 epinephrine (SPGB group) or sterile normal saline (control group). Mean arterial blood pressure was maintained at $60-70 \mathrm{mmHg}$ by using nitroglycerine. Intraoperative MAP and heart rate, Nitroglycerine and propranolol consumption, blood loss, average category scale, emergence time were recorded. Also, pre and postoperative plasma B-endorphin, VAS and time of the first request for analgesia, the total dose of meperidine consumption in the first 24 hours postoperatively, patient's satisfaction and postoperative complication were recorded.

Results: Sphenopalatine ganglion block group showed decrease in blood loss $(\mathrm{P}<0.001)$, ACS $(\mathrm{P}<0.01)$, nitroglycerine consumption $(\mathrm{P}<0.0001)$ and emergence time $(\mathrm{P}<0.001)$. At $\mathrm{PACU}$, visual analog pain score were lower in SPGB at $0,1,6(\mathrm{P}<0.001)$, there were a high difference between two groups in $\mathrm{B}$-endorphin levels $(\mathrm{P}<0.001)$ and also in dose of meperidine, \% of patients needs analgesia and patients satisfaction $(\mathrm{P}<0.002)$,

Conclusion: Use of sphenopalatine ganglion block with general anesthesia is a safe and effective technique, it contributes in adequate intra and postoperative analgesia needed for stabilization of hemodynamics with less blood loss, improving the quality of surgical field instead of controlled hypotensive technique during endoscopic endo-nasal trans-sphenoidal hypophysectomy.

Keywords: Postmenopausal bleeding; Endometrial Flushing; Endometrial Brush Cytology; Endometrial carcinoma

\section{INTRODUCTION}

Intraoperative bleeding is the main problem for anesthesiologists and surgeons, especially during the endoscopic transsphenoidal hypophysectomy. The most preferred minimally invasive technique for patients with pituitary adenoma is the endoscopic endonasal transsphenoidal approach (EETA) as it is also used for the treatment of patients with various skull base lesions. ${ }^{1,2}$ It is a less traumatic procedure, the surgical field in these endoscopic surgeries is very narrow and surrounded by vital structures. Even a small amount of blood in the surgical field can stain the tip of the endoscope and obscures the anatomy of the surgical field. Repeated staining, poor visualization in narrow and delicate field prolongs the procedure, increases the risk of injury to adjacent vital structures and postoperative complications. So, the bloodless field is mandatory for the surgeon. ${ }^{3}$ Anesthetic techniques to minimize bleeding during the trans nasal endoscopic surgery is of primary importance for a safe and effective procedure. In addition to optimizing surgical safety and minimizing intra-operative and post-operative complications, a dry surgical field with better visualization during trans nasal endoscopic surgery 
will also reduce operative times and shorten postoperative convalescence. Various methods have been advocated to reduce intra-operative bleeding during endoscopic trans nasal resection of pituitary adenomas including patient placement in the reverse Trendelenburg position increases the depth of anesthesia, infusion of vasodilators, premedication with beta-blockers, application of total intravenous anesthesia (TIVA), and controlled hypotension. ${ }^{4}$

Controlled hypotensive anesthesia can be defined as the reduction of mean arterial pressure(MAP) to 50$65 \mathrm{mmHg}$, with the primary aim to improve surgical visibility without compromising perfusion to vital $\operatorname{organs}^{3,4}$. Many anesthesiologists do not prefer to apply controlled hypotension due to its affection for cerebral perfusion. ${ }^{5}$ However, with all these techniques, excessive bleeding still remains a problem during the EETA. So, the injection of local anesthetic with adrenaline around the sphenopalatine ganglion (SPG) to induce vasoconstriction of the sphenopalatine artery, is widely performed after induction of general anesthesia and before the beginning of surgical procedure. ${ }^{6,7,8,9,10}$

The sphenopalatine ganglion (SPG); is a large extracranial and one of four parasympathetic ganglia with multiple neural roots, including autonomic, sensory, and motor. SPG is located in the pterygopalatine fossa, posterior to the middle nasal turbinate under a 1-1.5 mm layer of a mucous membrane, connective tissue and anterior to the pterygoid canal. This superficial location makes the block easily performed with topical anesthetic or by injection. SPG contains the cell bodies of the postganglionic parasympathetic neurons. Postganglionic sympathetic neurons, as well as somatic sensory afferent branches of the maxillary division of the trigeminal nerve, also pass through the ganglion (but do not terminate), so it is connected directly to the superior cervical sympathetic ganglion. Postganglionic parasympathetic postsynaptic neurons supply the lacrimal and nasal glands as well as paranasal sinuses, palate, and upper pharynx areas by ophthalmic and maxillary divisions of the trigeminal nerve. Orbital projections from the SPG provide postganglionic parasympathetic and sympathetic innervation of the major meningeal and cerebral vasculature. The SPG is a crossroad for the trigeminal, facial, and autonomic nerves and with possible distant autonomic actions, all of which may be inhibited by blockade of the SPG. ${ }^{11}$

This study is aimed to evaluate the effect of bilateral sphenopalatine ganglion block (SPGB) under general anesthesia on the intra-operative hemodynamic stability at the target MAP, HR (60-70 $\mathrm{mmHg}$ ) and surgical field bleeding as a primary outcome and postoperative pain relief as a secondary outcome.

\section{PATIENTS AND METHODS}

This prospective, randomized, double-blinded, controlled study was carried out on thirty patients aged 22-55 years, American Society of Anesthesiologists(ASA) physical status I or II scheduled for elective endoscopic trans-nasal resection of pituitary adenoma under general anesthesia in Al-Azhar University Hospital, Egypt from October 2017-2019. After approval of the local institutional ethical committee, and informed consent from all participants, patients were randomly assigned according to Sequentially Numbered, Opaque, Sealed Envelopes (SNOSE) method to one of two equal groups ( $n=15$, for each), placebo group (control) or SPGB group.

Exclusion criteria: Patients who had severe cardiovascular abnormalities, disturbed level of consciousness, bleeding disorders, elevated intracranial pressure, hepatic and renal disorders, obese patients with body mass index $>30 \mathrm{~kg} / \mathrm{m} 2$, patients on anticoagulants, non-steroidal antiinflammatory drugs or patients received analgesia or steroids in the previous 48hours, and patients with history of alcohol or drug abuse. All patients were checked 24hours before surgery to fulfill the inclusion criteria of the study through history taking, reviewing results of routine investigations and clinical examination for endocrinal functions, increased intracranial pressure and all patients received the appropriate preoperative therapy. All patients were explained and familiarized about the study including the use of visual analog scale for pain assessment $(0$ as no pain to 10 as the worst imaginable pain) and for patient satisfaction $(0=$ excellent, $1-3=$ good, $4-7=$ poor, $\quad 8$ $10=$ very poor).

On arrival at the operating theatre, a peripheral intravenous line was inserted with $18 \mathrm{G}$ intravenous cannula and two patients' groups were monitored by standard monitoring devices including end-tidal carbon dioxide (EtCO2), electro-cardiograph (ECG), non-invasive arterial blood pressure (NIBP) and pulse oximetry. All patients were given intravenous midazolam $0.02 \mathrm{mg} / \mathrm{kg}$ as premedication.

All patients were given general anesthesia, after preoxygenation, anesthesia was induced with IV fentanyl $1 \mu \mathrm{g} / \mathrm{kg}$, propofol $2 \mathrm{mg} / \mathrm{kg}$, rocuronium $0.6 \mathrm{mg} / \mathrm{kg}$ was used for endotracheal intubation, and then the oropharyngeal pack was applied and the monitoring of blood pressure and HR were adjusted at $5 \mathrm{~min}$ interval through the study. Maintenance of anesthesia was achieved with a mixture of oxygen: air (1:1), isoflurane at 1.2-2.4 minimum alveolar anesthetic concentration (MAC) and intermittent boluses of rocuronium was given $0.1 \mathrm{mg} / \mathrm{kg}$ if required. Ventilation must be controlled to maintain the EtCO2 within $30-35 \mathrm{mmHg}$ and MAP at 60 $70 \mathrm{mmHg}, \mathrm{HR}$ at $60-70$ beats/min to avoid the cerebral ischemia. Intraoperative fluid administration was $3 \mathrm{ml} / \mathrm{kg} / \mathrm{h}$ of ringer solution. If bradycardia ( $\mathrm{HR}<60$ beats/min) occurred, it was treated with intravenous increments of $0.2-0.3 \mathrm{mg}$ atropine, hypotension (MAP $<60 \quad \mathrm{mmHg}$ ) was managed with fluid challenges. If MAP $>70 \mathrm{mmHg}$, we must be increase depth of anesthesia by adjusting the MAC of isoflurane, IV infusion of paracetamol $15 \mathrm{mg} / \mathrm{kg}$ (perfalgan $1 \mathrm{gm}$ ) and if persistent hypertension may use nitroglycerine infusion 0.5 to $10 \mu \mathrm{g} / \mathrm{kg} / \mathrm{min}$ according to patient response, and if tachycardia (HR $>90$ beat $/ \mathrm{min}$ ) occurred, 0.2- 0.3 mg increments of propranolol was given to maintain $\mathrm{HR}$ at $60-70$ beat $/ \mathrm{min}$. After stabilization of anesthesia, basic values of MAP and HR were recorded and patients were randomly allocated by the SNOSE method to one of two 
groups, placebo(control) group and SPGB group $(n=15$, for each). Patients in both groups were prepared for bilateral injection of sphenopalatine ganglion 10 minutes before the beginning of the surgical procedure.

The resident of anesthesia who had no rule in the study prepared in two identical syringes; $2 \mathrm{ml}$ of $2 \%$ lidocaine: 1:200000 epinephrine (SPGB group) or $2 \mathrm{ml}$ of sterile normal saline (placebo in control group), and the injection in all patients was performed by the ENT surgeon who will be unaware of the content of the syringes.

The technique of bilateral sphenopalatine ganglion block

All patients placed in a $15^{\circ}$ reverse Trendelenburg position, the peripheral blockade is obtained by means of a local anesthetic that should be delivered as closely possible to the SPG; the nose is swabbed by an antibiotic and antiseptic solution. All nasal cavity between the middle and inferior turbinate, from nares to posterolateral wall of the nasopharynx was anesthetized topically ( $2 \%$ lidocaine with 1:200,000 epinephrine) using cotton-tipped applicators. A 20 -gauge/5-in, spinal needle was used after bending $2-3 \mathrm{~mm}$ of its tip along the port side with a sterile needle holder to form a $45^{\circ}$ angle advanced with the bevel pointer facing laterally. Under endoscopic control $\left(0^{\circ}\right.$ optics, $4 \mathrm{~mm}$ diameter), the needle was inserted between middle and inferior turbinate, according to allocated group and after negative aspiration of blood or air, $2 \mathrm{ml}$ of either 2\% lidocaine (with 1/200,000 epinephrine) in SPGB group or normal saline in control group was injected into the nasal mucosa just behind and over middle turbinate tail, where the pterygopalatine fossa is deeply located, The needle was flushed and removed. A sterilized cotton-tipped applicator was impacted to assure no bleeding after needle removal. After 5-10 minutes from a successful block on both sides, the patient was submitted for endoscopic hypophysectomy.

The same surgical team performed all operations to ensure consistency in the evaluation of the operative field. The surgical team and the anesthetist managing the patients intraoperatively were blinded to the drug being administered.

After stabilization of MAP and HR at target level for $15 \mathrm{~min}$, the surgeon, blinded to group assignment and hemodynamic parameters, was requested to evaluate the quality of the surgical field using a pre-defined average category scale(from 0 to 5), the best category scale values for quality of surgical field were pre-determined to be 2 and 3 (Table 1)

Grade assessment

\footnotetext{
0 : No bleeding in the nasopharynx or a vessel

1: Slight bleeding, no suctioning of blood required

2: Slight bleeding, occasional suctioning required. Surgical field not threatened

3: Slight bleeding, frequent suctioning required. Bleeding threatens surgical field a few seconds after suction is removed

4: Moderate bleeding, frequent suctioning required. Bleeding threatens surgical field directly after suction is removed

5: Severe bleeding, constant suctioning required. Bleeding appears faster than can be removed by suction. Surgical field severely threatened and surgery usually not possible
}

Table 1: average category scale for assessment of surgical field (adapted from Fromme et al.) ${ }^{\mathbf{1 2}}$

\section{Surgical technique}

Right nostril is the preferred one to go through but may change according to the pre-operative CT imaging assessment of the patient's nasal passageway and a $4 \mathrm{~mm} 0^{0}$ endoscope was used first during the nasal phase. The middle turbinate was lateralized using a freer elevator, sphenoidal ostium was identified and enlarged with Kerrison rongeurs after dissecting the mucosa as a naso-septal flap which may be needed for reconstruction.

The sphenoidal rostrum and posterior vomer were removed to open the whole anterior wall of the sphenoid sinus and also inter-sphenoid septum only sparing little part of the vomer as a guide for the neurosurgeon. Inside the sphenoid sinus, we identify the sellar floor bulge and eminences of bilateral carotid arteries and optic nerves and bilateral Optic-Carotid Recesses.

Removal of the floor of the sella turcica was done using a diamond drill and $1 \mathrm{~mm}$ Kerrison rongeurs and dural opening in a cruciate manner using special Sharp pituitary knife. Excision of the tumor by pituitary curette piece by piece starting posteriorly, laterally then finally the anterior part to avoid diaphragma sellae early exposure.

The $0^{0}$ endoscope was used to guide the intranasal dissection and initial tumor resection. Once tumor resection was completed or residual tumor was outside the field of view, the $0^{0}$ endoscope was withdrawn and a $4 \mathrm{~mm} 30^{\circ}$ endoscope was inserted. Rotating the $30^{\circ}$ endoscope clockwise and counterclockwise provides visualization of suprasellar and para-sellar tumor extension, including invasion into the cavernous sinus if present.

The area was irrigated, and hemostasis was obtained. An abdominal fat graft was harvested and used to reconstruct the sellar defect, which was then sealed using fibrin glue, fat, and fibrillar packing. In the case of CSF leak, the nasoseptal flap may be needed. Only a small gauze dressing was placed to collect any residual blood or debris.

At the end of the surgery, the oropharyngeal pack was removed, isoflurane and all infusions were switched off. A combination of neostigmine (0.05$0.08 \mathrm{mg} / \mathrm{kg}$ ) and atropine $0.01 \mathrm{mg} / \mathrm{kg}$ was administered to reverse the residual neuromuscular blockade. Patients were allowed to recover spontaneously, extubated fully awake and smoothly, then shifted to the post-anesthesia care unit (PACU) under closed observation until the patient fulfill the score $\geq 9$ according to the modified Alderet score from(zero to ten). ${ }^{13}$ Table 2

Different parameters were recorded in both groups as follows:

- Intraoperative MAP and HR values every 15 min.

- The dose of nitroglycerine and propranolol needs to achieve the target MAP and HR (60-70mmhg).

- Intraoperative ACS (from 0 to 5) every $30 \mathrm{~min}$.

- Amount of intraoperative blood loss (calculated by measuring the volume of the blood in the suction reservoir minus the normal saline used to wash the surgical field).

-The time of emergence (beginning from discontinuation of anesthetic and adjuvant agents
Anesthesia

ENT

Neurosurgery 
until the patient responded to verbal command) and duration of the surgery.

-VAS (0-10), immediately after the operation, then at $1,6,12 \mathrm{hrs}$., VAS $\geq 4$ was managed by IV dose of $25 \mathrm{mg}$ meperidine, number of doses and patients who received meperidine in both groups.

- The time to $1^{\text {st }}$ request for analgesia.

- Patient's satisfaction score (excellent, good, poor). - Postoperative complications (nausea, vomiting (PONV), bleeding, headache, visual disturbances, agitation or somnolence). Plasma Beta-endorphin (BE) level: Blood samples were taken 15 min before surgery and immediately after PACU admission before receiving any type of analgesia. The plasma $\mathrm{BE}$ assay was performed similarly to the work of Bruehl et al., $2007^{14}$, $4 \mathrm{~mL}$ of venous blood was collected in Vacutainer tubes containing anticoagulant ethylenediaminetetraacetic acid (EDTA) and immediately stored in ice. Samples were processed in a cool centrifuge $\left(0-4^{\circ} \mathrm{C}\right)$ at 3000rpm for 15 minutes (within 30 minutes of collection). Plasma was extracted and stored at $-80^{\circ} \mathrm{C}$ until assays were performed. Plasma BE levels were analyzed in the same laboratory using a commercially available radioimmunoassay kit, the detection limit was $0.1 \mathrm{ng} / \mathrm{ml}$.

\begin{tabular}{|l|c|}
\hline \multicolumn{1}{|c|}{ Description } & Score \\
\hline Consciousness & \\
Fully awake and oriented (name, place, date) & 2 \\
Arousable on calling & 1 \\
Not responding & 0 \\
\hline Activity & \\
Moves all four extremities voluntary or on & 2 \\
command & 1 \\
Moves two extremities & 0 \\
Unable to move extremities & \\
\hline Respiration & 2 \\
Breathes deeply and coughs freely & 1 \\
Dyspnea, limited breathing or tachypnea & 0 \\
Apnea or on mechanical ventilation & \\
\hline Circulation & 2 \\
Blood pressure $\pm 20 \%$ pre-anesthetic level & 1 \\
Blood pressure $\pm 20-49 \%$ pre-anesthetic level & 0 \\
Blood pressure $\pm 50 \%$ pre-anesthetic level & \\
\hline Oxygen saturation & 2 \\
SpO2 $>92 \%$ on room air & 1 \\
Supplemental O2 is required to keep saturation & 0 \\
>90\% & \\
SpO2 <92\% with O2 supplementation & 10 \\
\hline Maximum score & \\
\hline
\end{tabular}

Table 2: Postoperative modified Alderet recovery score

\section{Sample size calculation}

Using pass 11 program for sample size calculation; the sample size was calculated according to a results from the previous study done by Ali et al. $(2010)^{9}$ who stated that emergence time was significantly shorter in block group than non-block group [5.4 (1.21) min versus 7.92 (1.88) min with mean difference of 2.52. The ratio between the two groups was set to 1:1. A sample size of 11 patients in each group achieves $95 \%$ power to detect the difference at 0.05 significance level.

Statistical analysis

Data were collected, revised, coded and entered into the Statistical Package for Social Science (IBM SPSS) version 23. The quantitative data were presented as mean, standard deviations and ranges when their distribution found parametric and median with inter-quartile range (IQR) when their distribution found nonparametric. Also, qualitative variables were presented as numbers and percentages. The comparison between groups regarding qualitative data was done by using the Chi-square test. The comparison between two independent groups with quantitative data and parametric distribution was done by using an independent t-test while data with non-parametric distribution were done by using the Mann-Whitney test. The confidence interval was set to $95 \%$ and the margin of error accepted was set to $5 \%$. So, the pvalue was considered significant at the level of $<0.05$.

\section{RESULTS}

The thirty patients enrolled in this study completed it, demographic and operative data were comparable between both groups, although the duration of surgery was shorter in the SPGB group but with no statistical significance. Emergence time was significantly shorter in the SPGB group $(7.07 \pm 1.16)$ than the control group $(8.80 \pm 1.37), \mathrm{P}<0.001$. (Table 3, Figure 1)

\begin{tabular}{|l|l|l|l|l|}
\hline & $\begin{array}{l}\text { Control } \\
\text { group } \\
(\mathbf{n = 1 5})\end{array}$ & $\begin{array}{l}\text { SPGB group } \\
(\mathbf{n = 1 5})\end{array}$ & $\begin{array}{l}\text { Test } \\
\text { value }\end{array}$ & $\begin{array}{l}\text { P- } \\
\text { value }\end{array}$ \\
\hline Age (years) & $48.50 \pm 8.59$ & $46.00 \pm 9.40$ & $0.760 \bullet$ & 0.453 \\
\hline $\begin{array}{l}\text { Sex } \\
\text { Male } \\
\text { Female }\end{array}$ & $\begin{array}{l}11(73.3 \%) \\
4(26.7 \%)\end{array}$ & $\begin{array}{l}12(80.0 \%) \\
3(20.0 \%)\end{array}$ & $0.186^{*}$ & 0.666 \\
\hline $\begin{array}{l}\text { ASA status } \\
\text { I } \\
\text { II }\end{array}$ & $\begin{array}{l}9(60.0 \%) \\
6(40.0 \%)\end{array}$ & $\begin{array}{l}8(53.3 \%) \\
7(46.7 \%)\end{array}$ & $0.136^{*}$ & 0.712 \\
\hline Weight (kg) & $81.50 \pm 3.35$ & $83.50 \pm 4.35$ & $1.411 \bullet$ & 0.169 \\
\hline Height (cm) & $165 \pm 5.46$ & $167 \pm 2.29$ & $1.308 \bullet$ & 0.201 \\
\hline $\begin{array}{l}\text { Types of pituitary } \\
\text { adenoma (n) } \\
\text { Non-functioning } \\
\text { adenoma } \\
\text { Functioning adenoma }\end{array}$ & 9 & 8 & $0.136^{*}$ & 0.712 \\
\hline $\begin{array}{l}\text { Duration of surgery } \\
\text { (min) }\end{array}$ & $203.4 \pm 29.34$ & $\begin{array}{l}193.75 \pm 33.9 \\
1\end{array}$ & $0.833 \bullet$ & 0.412 \\
\hline $\begin{array}{l}\text { Emergence times } \\
\text { (min.) }\end{array}$ & $8.80 \pm 1.37$ & $7.07 \pm 1.16$ & $3.731 \bullet$ & $\begin{array}{l}0.001 \\
\# \#\end{array}$ \\
\hline
\end{tabular}

Table 3: Demographic and operative data (Mean \pm standard deviation (SD)), ratio or number

$\because$ Independent t-test; $*$ : Chi-square test. $P>0.05: N S \quad \# P \leq 0.05: S \quad \# P<0.01: H$

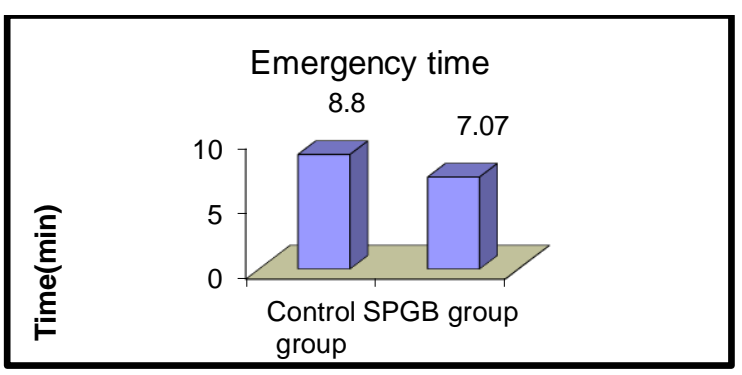

Fig.1: Bar chart representing mean emergence times (min.) in both group 
Hemodynamic variables:

Mean values of intraoperative MAP at different times were comparable in both groups whereas, all patients $(100 \%)$ in control group versus 2 patients $(13.3 \%)$ in SPGB group $(\mathrm{P}<0.0001)$ needed

a supplemented nitroglycerine, not exceeding the dose of $1 \mu \mathrm{g} / \mathrm{kg} / \mathrm{min}$ to reach the target MAP $(60$ $70 \mathrm{mmHg}$ ), which was fluctuating in the control group compared to SPGB group (Table 4, Figure 2). $100 \%$ of patients in both groups received $1 \mathrm{gm}$ of Perfalgan.

\begin{tabular}{|c|c|c|c|c|}
\hline & $\begin{array}{l}\text { Control } \\
\text { group } \\
(n=15)\end{array}$ & $\begin{array}{l}\text { SPGB } \\
\text { group } \\
(n=15)\end{array}$ & $\begin{array}{l}\text { Test } \\
\text { value• }\end{array}$ & p-value \\
\hline $\begin{array}{l}\mathrm{T}_{1} \quad(30 \quad \mathrm{~min} \\
\text { intraoperative) }\end{array}$ & $3.4 \pm 0.85$ & $2.7 \pm 0.93$ & 2.152 & $0.040^{\#}$ \\
\hline $\begin{array}{l}\mathrm{T}_{2} \quad(60 \mathrm{~min} \\
\text { intraoperative })\end{array}$ & $3.6 \pm 0.89$ & $2.6 \pm 0.76$ & 3.309 & $0.003^{\#}$ \\
\hline $\begin{array}{l}\mathrm{T}_{3} \quad(90 \quad \mathrm{~min} \\
\text { intraoperative) }\end{array}$ & $3.4 \pm 0.74$ & $2.8 \pm 0.56$ & 2.504 & $0.018^{\#}$ \\
\hline $\begin{array}{l}\mathrm{T}_{4} \quad(120 \quad \mathrm{~min} \\
\text { intraoperative })\end{array}$ & $3.3 \pm 0.95$ & $2.6 \pm 0.83$ & 2.149 & $0.040^{\#}$ \\
\hline $\begin{array}{l}\mathrm{T}_{5} \quad(150 \mathrm{~min} \\
\text { intraoperative })\end{array}$ & $3.4 \pm 0.72$ & $2.8 \pm 0.63$ & 2.429 & $0.022^{\#}$ \\
\hline $\begin{array}{l}\mathrm{T}_{6} \text { (180 min } \\
\text { intraoperative) }\end{array}$ & $3.8 \pm 0.64$ & $2.9 \pm 0.66$ & 3.791 & $0.001^{\# \#}$ \\
\hline $\begin{array}{l}\text { Intraoperative } \\
\text { blood loss } \\
(\mathrm{mL})\end{array}$ & $\begin{array}{l}225.30 \\
\pm 26.55 \\
\end{array}$ & $\begin{array}{l}110.40 \quad \pm \\
32.50\end{array}$ & 10.604 & $\begin{array}{l}<0.001^{\#} \\
\#\end{array}$ \\
\hline $\begin{array}{l}\text { Patients } \\
\text { requiring } \\
\text { nitroglycerine } \\
(\mathrm{n}(\%)\end{array}$ & $15(100 \%)$ & $2(13.3 \%)$ & $22.941^{*}$ & $<0.0001$ \\
\hline
\end{tabular}

Table 4: The average category scale (ACS) for quality of surgical field, intra-operative blood loss and nitroglycerin consumption. Values are means and standard deviation (SD)

$\because$ Independent $t$-test $\quad P>0.05: N S$
${ }^{\#} P \leq 0.05: S \quad{ }^{\# \#} P<0.01: H S$

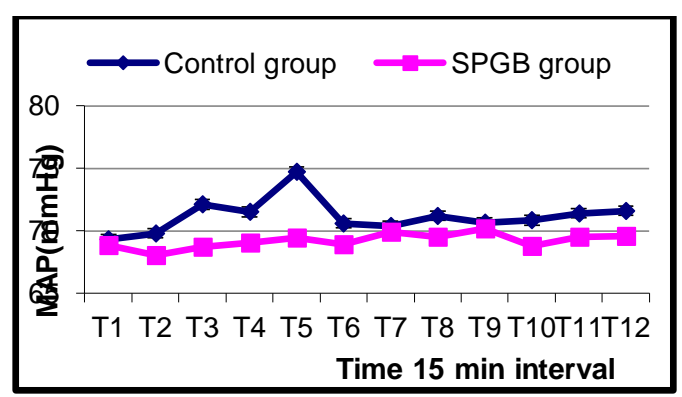

Fig.2: Chart representing the intraoperative MAP changes at different times in both groups

Regarding intraoperative heart rate at different times, there was no statistically significant difference between the two groups, and the patients in both groups did not need B-blockers to control it. (Figure 3)

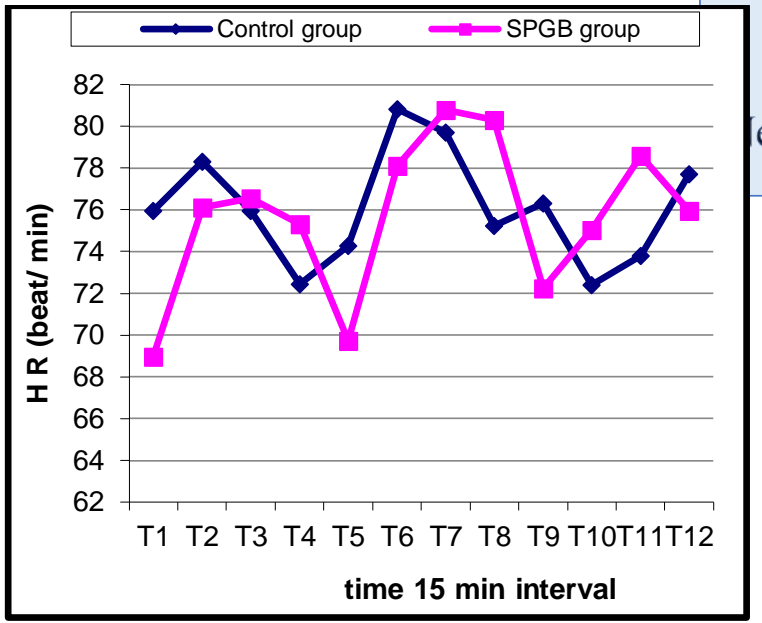

ENT

Fig.3: Chart representing the intraoperative HR changes at different times in both groups

Concerning the average category scale for the quality of the surgical field, it was significantly low at all recorded time intervals in the SPGB group with improving the visibility to the surgical field when compared to the control group $(\mathrm{P}<0.05)$. Intraoperative blood loss was significantly high in the control group $(225.30 \pm 26.55 \mathrm{ml})$ when compared to the SPGB group $(110.40 \pm 32.50 \mathrm{ml}),(\mathrm{P}<0.001)$ and no patients in both groups suffered from acute or excessive blood loss. (Table 5, Figure 4,5)

\begin{tabular}{|c|c|c|c|c|c|c|}
\hline & & $\begin{array}{c}\text { Control } \\
\text { group } \\
\text { No. }= \\
15\end{array}$ & $\begin{array}{c}\text { SPGB } \\
\text { group } \\
\text { No. = } \\
15\end{array}$ & $\begin{array}{l}\text {-Test } \\
\text { value }\end{array}$ & $\begin{array}{l}\text { P- } \\
\text { value }\end{array}$ & Sig. \\
\hline $\begin{array}{c}\text { Immediat } \\
\text { ely post- } \\
\text { operative }\end{array}$ & $\begin{array}{c}\text { Median } \\
(\mathrm{IQR}) \\
\text { Range } \\
\end{array}$ & $\begin{array}{c}5(4-5) \\
4-6 \\
\end{array}$ & $\begin{array}{c}2(1-3) \\
0-3 \\
\end{array}$ & -4.788 & 0.00 & HS \\
\hline $\begin{array}{c}1 \mathrm{~h} \\
\text { Post- } \\
\text { operative }\end{array}$ & $\begin{array}{l}\text { Median } \\
\text { (IQR) } \\
\text { Range } \\
\end{array}$ & $\begin{array}{c}6(5-6) \\
5-6 \\
\end{array}$ & $\begin{array}{c}3(3-3) \\
2-3 \\
\end{array}$ & -5.019 & 0.00 & HS \\
\hline $\begin{array}{c}\text { 6h } \\
\text { Post- } \\
\text { operative }\end{array}$ & $\begin{array}{c}\text { Median } \\
\text { (IQR) } \\
\text { Range } \\
\end{array}$ & $\begin{array}{c}4(4-5) \\
4-5 \\
\end{array}$ & $\begin{array}{l}2(2-3) \\
2-3\end{array}$ & -4.827 & 0.00 & HS \\
\hline $\begin{array}{c}12 \mathrm{~h} \\
\text { Post- } \\
\text { operative }\end{array}$ & $\begin{array}{l}\text { Median } \\
\text { (IQR) } \\
\text { Range }\end{array}$ & $\begin{array}{c}3(3-4) \\
2-4\end{array}$ & $\begin{array}{l}3(3-4) \\
2-4\end{array}$ & -0.268 & 0.789 & NS \\
\hline
\end{tabular}

Table 5: Postoperative visual analogue pain score in both groups. Values are Median (IQR) and Range.

P-value $>0.05$ : Non significant (NS); P-value <0.05:

Significant (S); P-value< 0.01: highly significant (HS)

$\because$ Mann Whitney test IQR (Interquartile range)

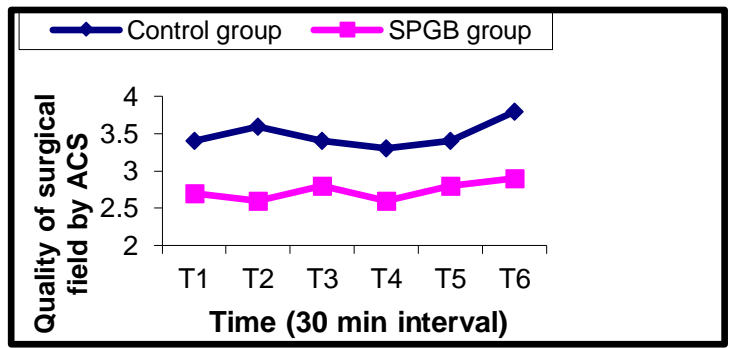

Fig. 4: Chart representing average category scale (ACS) for quality of surgical field in the two groups 


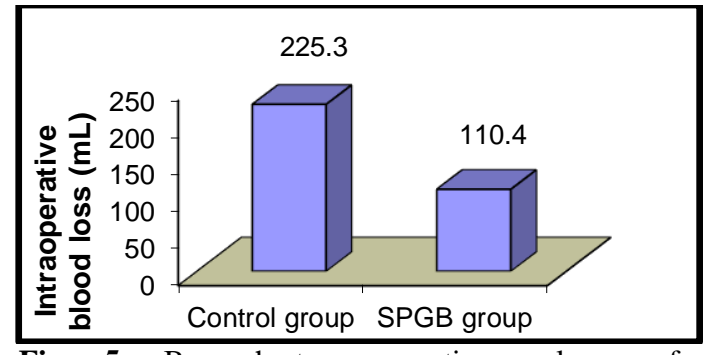

Fig. 5: Bar chart representing volume of intraoperative blood loss $(\mathrm{mL})$ in both groups

\section{Postoperative pain assessment}

VAS was lower in SPGB group than control group at $0,1,6 \mathrm{hrs}(\mathrm{P}<0.0001)$ and no significant value at $12 \mathrm{hrs}$ postoperatively $(\mathrm{P}>0.05)$ (table5). The time to $1^{\text {st }}$ request of analgesia were statistically higher in SPGB group $(6.8 \pm 1.3)$ than control group $(1.1 \pm 1.6)$, $(\mathrm{P}<0.001)$ (table6), doses of analgesia during the first 24hours in SPGB group showed higher prevalence either to the cases who didn't need analgesia or those who received a one dose of meperidine $(25 \mathrm{mg}$ ) in comparison to control group which showed a higher prevalence of cases who received two doses of meperidine( $25 \mathrm{mg}$ each dose), five cases in SPGB group didn't take any analgesia in the first 12 hours after operation $(\mathrm{P}<0.002)$. (Table 6, Figure 6)

\begin{tabular}{|c|c|c|c|c|}
\hline $\begin{array}{c}\text { Doses of } \\
\text { analgesia } \\
\text { (No., \%) }\end{array}$ & $\begin{array}{l}\text { Control } \\
\text { group } \\
(\mathbf{n}=15)\end{array}$ & $\begin{array}{l}\text { SPGB } \\
\text { group } \\
(n=15)\end{array}$ & $\begin{array}{l}\text { Test } \\
\text { value* }\end{array}$ & $P$-value \\
\hline $\begin{array}{c}\text { No need } \\
\text { for } \\
\text { analgesia }\end{array}$ & $0(0 \%)$ & $\begin{array}{l}5 \\
(33.3 \%)\end{array}$ & \multirow{3}{*}{12.222} & \multirow{3}{*}{$0.002^{\#}$} \\
\hline $\begin{array}{c}\text { One } \\
\text { meperdine } \\
\text { ampoule } \\
(25 \mathrm{mg} \mathrm{Iv})\end{array}$ & $\begin{array}{l}8 \\
(53.3 \%)\end{array}$ & $\begin{array}{l}10 \\
(66.7 \%)\end{array}$ & & \\
\hline $\begin{array}{c}\text { Two } \\
\text { meperdine } \\
\text { ampoules } \\
(25 \mathrm{mg} \mathrm{Iv})\end{array}$ & $\begin{array}{l}7 \\
(46.7 \%)\end{array}$ & $0(0 \%)$ & & \\
\hline $\begin{array}{l}\text { Time of } 1^{\text {st }} \\
\text { request of } \\
\text { analgesia } \\
\text { (Hours) } \\
\text { Mean } \pm \text { SD }\end{array}$ & $\begin{array}{ll}1.1 & \pm \\
1.6 & \end{array}$ & $\begin{array}{ll}6.8 & \pm \\
1.3 & \end{array}$ & $\bullet 10.708$ & $<0.001^{\# \#}$ \\
\hline
\end{tabular}

Table 6: Doses of analgesia and time of $1^{\text {st }}$ request of analgesia in the two groups (frequencies (n), percentages $(\%)$

$$
\begin{aligned}
& \text { *: Chi-square test; } \quad \because \text { Independent t-test; } \quad P>0.05 \text { : } \\
& \text { NS } \quad{ }^{\#} P \leq 0.05: S \quad{ }^{\#} P<0.01: H S
\end{aligned}
$$

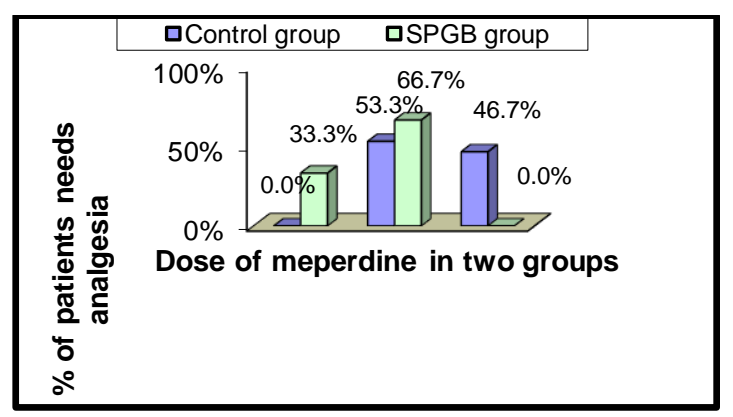

Fig. 6: Bar chart representing dose of meperidine and $\%$ of patients needs analgesia in both groups
Regards the plasma Beta-endorphin levels, there was no significant difference between the two groups in preoperative time. Post-operatively, the control group showed a higher mean Beta-endorphin level than the SPGB group $(\mathrm{P}<0.001)$. In regard to the \% change, the control group showed a statistically higher mean \% increase in Beta-endorphin level than the SPGB group $(\mathrm{P}<0.001)$. (Table7, Figure 7)

\begin{tabular}{|c|l|l|l|l|}
\hline $\begin{array}{c}\text { Beta- } \\
\text { endorphin } \\
\text { level }(\mathbf{n g} / \mathbf{m l})\end{array}$ & $\begin{array}{l}\text { Contr } \\
\text { ol } \\
\text { group } \\
(\mathbf{n = 1 5})\end{array}$ & $\begin{array}{l}\text { SPGB } \\
\text { group } \\
(\mathbf{n = 1 5})\end{array}$ & $\begin{array}{l}\text { Test } \\
\text { value• }\end{array}$ & P-value \\
\hline Pre-operative & $\begin{array}{l}3.08 \pm \\
0.19\end{array}$ & $\begin{array}{l}3.13 \pm \\
0.18\end{array}$ & 0.740 & 0.465 \\
\hline $\begin{array}{c}\text { Post- } \\
\text { operative }\end{array}$ & $\begin{array}{l}6.26 \pm \\
0.76\end{array}$ & $\begin{array}{l}4.37 \pm \\
0.37\end{array}$ & 8.660 & $<0.001$ \\
\hline$\%$ change & $\begin{array}{l}103.2 \\
\pm 20\end{array}$ & $\begin{array}{l}39.6 \pm \\
12\end{array}$ & 10.561 & $<0.001$ \\
\hline
\end{tabular}

Table 7: Beta-endorphin levels in the two groups. Values are means and standard deviation (SD).

-Independent t-test; $\quad{ }^{\# \# ~ P<0.01: ~ H S ; ~ \% ~ c h a n g e ~ i s ~}$ calculated as: $\underline{\text { Post-operative level-Pre-operative level }} \times 100$ Pre-operative level

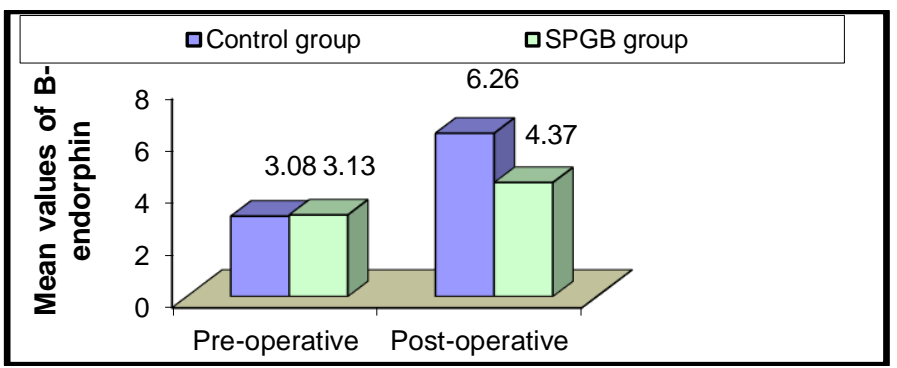

Fig. 7: Bar chart representing mean values of pre and post operative Beta-endorphin levels in the two groups

Postoperative patient satisfaction and complications

There was a significant difference between the two groups. SPGB group showed a higher prevalence of cases who reported excellent satisfaction. The control group showed a higher prevalence of cases who reported poor or good satisfaction $(\mathrm{P}<0.002)$

\begin{tabular}{|c|c|c|c|c|}
\hline $\begin{array}{l}\text { Satisfaction } \\
(n, \%)\end{array}$ & $\begin{array}{l}\text { Contro } \\
\text { l group } \\
(n=15)\end{array}$ & $\begin{array}{l}\text { SPGB } \\
\text { group } \\
(n=15)\end{array}$ & $\begin{array}{l}\text { Test } \\
\text { value }^{*}\end{array}$ & $\begin{array}{c}P \text { - } \\
\text { value }\end{array}$ \\
\hline Poor & $\begin{array}{l}7 \\
(46.7)\end{array}$ & $0(0)$ & \multirow{3}{*}{12.222} & \multirow{3}{*}{$\begin{array}{l}0.002 \\
\# \#\end{array}$} \\
\hline Good & $\begin{array}{l}8 \\
(53.3)\end{array}$ & $10(66.7)$ & & \\
\hline Excellent & $0(0)$ & $5(33.3)$ & & \\
\hline
\end{tabular}
(Table 8, Figure 8)

Table 8: Patients satisfaction in the two groups (frequencies (n), percentages $(\%)$ 


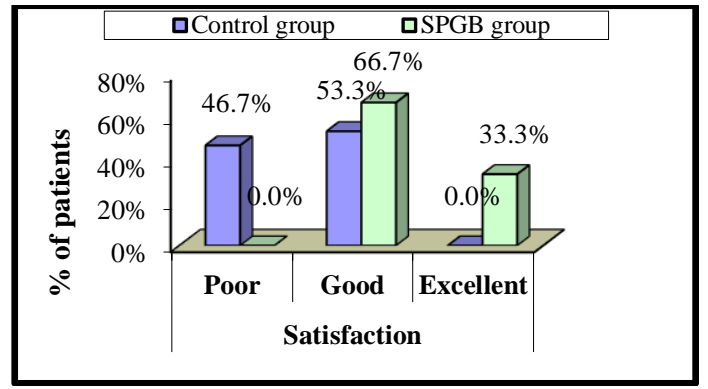

Fig. 8: Bar chart representing Patients satisfaction in the two groups.

Postoperative complications such as PONV $\{6$ patient (40\%) in the control group versus 2 patients $(6.6 \%)$ in SPGB group $\}$ and 9 patients $(60 \%)$ in the control group presented by postoperative headache versus no one in SPGB group $(\mathrm{P}<0.001)$.

\section{DISCUSSION}

The surgery and SPGB through EETA are supported by recent technological advancements, have been increasingly used over the last decade for the treatment of pituitary adenoma. ${ }^{1,2,6-10,15-22}$

The main goal of blood pressure control during ETSS was to achieve a dry surgical field to improve visibility and facilitate the surgical approach without complication. In the current study, the MAP, HR was maintained at target levels, with no significant differences between the two groups but it was non-fluctuated in the SPGB group by adjustment the ventilatory support and balanced anesthesia with no or minimal consumption of hypotensive agents compared to control group. The results of the present study resemble the outcomes of previous studies that investigate the effect of SPGB combined with general anesthesia in endoscopic trans-nasal resection of pituitary adenoma and sinonasal surgeries. ${ }^{9,16}$ On the other hand, Ismail and Anwar ${ }^{17}$ evaluating the effect of SPGB combined with general anesthesia in endoscopic sinus surgery and reported the decrease in HR in block group compared with the non-block group. Another studies ${ }^{18,19,22}$ performed the same surgery as Ismail and Anwar ${ }^{17}$ reported the decrease in both HR and MAP in block group compared with the non-block group.

In our study, the blood loss, and average category scale(ACS) for quality of the surgical field was significantly less in SPGB group compared to control group, these findings may be due to parasympathetic block allowing unopposed sympathetic activity to produce hemostasis obtained with SPGB ${ }^{11}$, these results agree with the previous studies $^{7,10,17,22}$. Opposed to these results, Ali et al ${ }^{9}$ and Cho et $\mathrm{al}^{24}$ found the ACS comparable in both groups with target MAP at $60-65 \mathrm{mmHg}$, but several studies $^{16-18,22}$ used hypotensive inhalational, bblockers and fentanyl in control group more than the SPGB group, whereas in our study we controlled the MAP and HR by nitroglycerine infusion rate according to patients need with all participants in control group versus 2 patients in SPGB group, patients undergoing general anesthesia have showna significant increase in beta-endorphins during surgery. This increase was effectively inhibited by the co-administration of fentanyl, so we administrated a booster dose of perfalgan instead of fentanyl for achieving balanced anesthesia.

These varieties in results might come from the different methods for control of intraoperative hemodynamics between nitroglycerine consumption or inhalational anesthesia, different types of bblockers and opioids.

As regards postoperative complication, our results presented by PONV $\{6$ patient $(40 \%)$ in control group versus 2 patients $(6.6 \%)$ in SPGB group and 9 patient $(60 \%)$ in control group suffered from postoperative headache versus no one patient in SPGB group, contralateral to these results, some studies, $9,23,24$ found no significant difference between two groups, on other hand our results coincide with the previous studies ${ }^{16,18,21,22}$, who found higher prevalence of PONV and headache in the control group than in the SPGB group.

In this study, the patient's satisfaction was higher in the SPGB group than the control group and also, all previous studies mentioned in this discussion either agreed with or was against the rest of our study found the patient's satisfaction was higher in SPGB group than the control group.

Complete and rapid awakening at the end of surgery is highly desirable for early neurological assessment. The previous studies ${ }^{9,16,17,18,22}$ coincides with the current study, which was a shorter emergence time in the SPGB group when compared to control group.

Beta-endorphins are primarily synthesized by the pituitary gland in response to physiologic stress such as painful stimuli. The function of Beta-endorphins is through various mechanisms in both the peripheral and central nervous system to relieve pain when bound to their mu-opioid receptors ${ }^{27}$. Studies of preand postoperative beta-endorphin levels were performed in various major surgeries ${ }^{25,26}$. It was found that both pre and postoperative plasma beta-endorphin levels positively correlate with postoperative pain intensity. Plasma B-endorphin levels are also elevated during surgery under general anesthesia but remain stable if regional anesthesia is administered before surgery. These observations suggest that increased circulating B-endorphin is an index of nociceptive input into the central nervous system ${ }^{27,28}$. So, we investigated the level of plasma Beta-endorphin among the two groups and found the higher level was in the control group compared to SPGB group, this result supported our results and all previous studies $^{9,16,17,18,22}$ regards the VAS, doses of analgesia requirements, the time to $1^{\text {st }}$ request of analgesia which was longer in SPGB group. And reflect the efficacy of bilateral SPGB in the endoscopic endonasal trans-sphenoidal surgery, which attributed to the adequate and extensive anesthesia achieved to the nasal cavity, paranasal sinuses and resting of structured supplied by nerves originated in SPG or traversing through it.

\section{CONCLUSION}

Uses of bilateral SPGB as adjuvants to general anesthesia is a safe and effective technique during endoscopic endo-nasal trans-sphenoidal hypophysectomy. It contributes inadequate
Anesthesia

ENT

Neurosurgery 
intraoperative analgesia needed for stabilization of hemodynamics during surgery, with less intraoperative blood loss, improving the visibility of the surgical field instead of controlled hypotensive technique. Also, it's decreased the postoperative pain, analgesic requirements and providing a faster recovery needed for early neurological evaluation.

\section{REFERENCES}

1. Saeki N, Horiguchi K, Murai H, et al. Endoscopic endonasal pituitary and skull base surgery. Neurol Med Chir (Tokyo) 2010; 50: 756-764.

2. Sheng N, Keqin L, Yi H, et al. Endoscopic endonasal transsphenoidal surgery for treating pituitary adenoma via a sub-septum mucosa approach. Int J Clin Exp Med 2015;8(4):5137-5143

3. Ha $T$, vanRenen $R$, Ludbrook $G$, et al. The relationship between hypotension, cerebral blood flow, and the surgical field during endoscopic sinus surgery. Laryngoscope. 2014; 124: 2224- 2230.

4. Suhitharan T, Sangeetha S, Kothandan H, et al. Anesthetic techniques and hemodynamic control for endoscopic sinus surgery: A retrospective analysis and review of the literature. Egypt $J$ Anaesth 2017; 33:9-14.

5. Choi W and Samman N. Benefits of deliberate hypotension in anesthesia: a systematic review. Int J Oral Maxillofac Surg 2008; 37: 687- 703.

6. Valdes C, Al Badaai Y, Bogado M, et al. Does pterygopalatine canal injection with local anesthetic and adrenaline decrease bleeding during functional endoscopic sinus surgery? J Laryngol Otol. 2014;128(9):814-817.

7. Wormald P, Athanasiadis T, Rees G, et al. An evaluation of the effect of pterygopalatine fossa injection with local anesthetic and adrenalin in the control of nasal bleeding during endoscopic sinus surgery. Am J Rhinol. 2005;19(3):288-292.

8. Shenoy V, Prakash N, Kamath P, et al. Is pterygopalatine fossa injection with adrenaline an effective technique for a better surgical field in fess? Indian J Otolaryngol Head Neck Surg 2017; 69:464-473.

9. Ali A, Sakr S and Rahman A. Bilateral sphenopalatine ganglion block as an adjuvant to general anesthesia during endoscopic trans-nasal resection of pituitary adenoma. Egypt J Anaesth. 2010;26(4):273-280.

10. Mathew R, Srinivasa C, Sathyanarayana V, et al. Role of pterygopalatine fossa block in achieving relatively bloodless field during endoscopic sinus surgery. Clin Rhinol Int J. 2015; 125:1010-1014

11. Kraynack B. Sphenopalatine ganglion block: An underutilized tool in pain management. Dev Anesthetics Pain Manag. 2017: 1(1):1-4.

12. Fromme G, MacKenzie R, Gould A, et al. Controlled hypotension for orthognathic surgery. Anesth Analg. 1986; 65:683-6.

13. Aldrete J. The post-anesthesia recovery score revisited. J Clin Anesth 1995; 7:89.

14. Brueh L, Stephen $\mathrm{N}$ et al. Trait anger expressiveness and pain-induced beta-endorphin release: support for the opioid dysfunction hypothesis. Pain. 2007:130(3): 208-15.

15. Torales J, Halperin I, Hanzu F, et al. Endoscopic endonasal surgery for pituitary tumors. Results in a series of 121 patients operated at the same center and by the same neurosurgeon. Endocrinol Nutr. 2014; 61: 410-6.

16. Ahmed $\mathrm{H}$ and Abu-Zaid E. Role of intraoperative endoscopic sphenopalatine ganglion block in sinonasal surgery. J Med Sci. 2007;7(8):1297-303.

17. Ismail $\mathrm{S}$ and Anwar H. Bilateral sphenopalatine ganglion block in functional endoscopic sinus surgery under general anesthesia. Alex J Anaesth Intensive Care 2005; 8:45-53.

18. Kesimci E, Öztürk L, Bercin S, et al. Role of sphenopalatine ganglion block for postoperative analgesia after functional endoscopic sinus surgery. Eur Arch Otorhinolaryngol 2012; 269:165-169.

19. Bhattacharyya S, Tewar, M, Ghosh S, et al. Evaluation of the efficacy of bilateral sphenopalatine ganglion block in endoscopic sinus surgery under general anesthesia: a randomized prospective controlled trial. Res Opin Anesth Intensive Care. 2016; 3:173-178.

20. Rezaeian A, Hashemi S and Dokhanchi Z. Effect of sphenopalatine ganglion block with bupivacaine on postoperative pain in patients undergoing endoscopic sinus surgery. Allergy Rhinol (Providence). 2019; 10: 1- 5.

21. Abubaker A and Al-Qudah M. The role of endoscopic sphenopalatine ganglion block on nausea and vomiting after sinus surgery. American Journal of Rhinology \& Allergy 2018: 32(5) 369373.

22. Gaafar T, El Sawy A, Zanfaly H, et al. Bilateral sphenopalatine ganglion block versus intravenous clonidine premedication for surgical field improvement and postoperative pain relief in endoscopic sino-nasal surgery. Zagazig University Medical Journal. 2019: 25(6), 847-857.

23. Ekici $\mathrm{N}$ and Alagöz S. The effectiveness of endoscopic sphenopalatine ganglion block in management of postoperative pain after septal surgery. International forum of allergy \& rhinology 2019 Sep 5. John Wiley \& Sons, Ltd.

24. Cho D, Drover D, Nekhendzy Vet al. The effectiveness of preemptive sphenopalatine ganglion block on postoperative pain and functional outcomes after functional endoscopic sinus surgery. Int Forum Allergy Rhinol. 2011; 1:212-218.

25. Matejec R, Ruwoldt R, Bodeker R, et al. Release of endorphin immunoreactive material under perioperative conditions into blood or cerebrospinal fluid: Significance for Postoperative Pain? Anesth Analg. 2003; 96:481-486.

26. Le Blanc-Louvry I, Coquerel A, Koning E, et al. Operative stress response is reduced after laparoscopic compared to open cholecystectomy: the relationship with postoperative pain and ileus. Digestive diseases and sciences. 2000;9: 17031713.

27. Sprouse-Blum A, Smith G, Sugai D, et al. Understanding endorphins and their importance in pain management. Hawaii medical journal. 2010 Mar;69(3):70.

28. Dionne R and McCullagh L. Enhanced analgesia and suppression of plasma $\beta$-endorphin by the $S(+)$ -isomer of ibuprofen. Clinical Pharmacology \& Therapeutics. 1998 Jun;63(6):694-701. 